\title{
Contribuições das Tecnologias da Informação e Comunicação à formação de professores de Matemática na modalidade a distância
}

\author{
Frederico da Silva Reis \\ Fausto Rogério Esteves
}

\begin{abstract}
Resumo: 0 presente artigo apresenta uma pesquisa que investigou as contribuições das Tecnologias da Informação e Comunicação para a Formação de Professores de Matemática na modalidade Educação a Distância. O referencial teórico-bibliográfico contempla trabalhos de Educação Matemática relacionados a Tecnologias, Formação de Professores e Educação a Distância. A pesquisa de campo foi realizada com alunos de Licenciatura em Matemática na modalidade a distância Universidade Federal de Ouro Preto (UFOP), a partir de atividades exploratórias sobre diversos conteúdos de Funções Polinomiais do $1^{\circ} \mathrm{e}$ do $2^{\circ}$ grau, Funções Trigonométricas e Funções Polinomiais, implementadas com utilização do software GeoGebra. As considerações finais apontam que as principais contribuições foram o desenvolvimento de competências e habilidades essenciais dos futuros professores, além de uma mudança de perspectiva em relação à sua futura prática pedagógica.
\end{abstract}

Palavras-chave: Tecnologias da Informação e Comunicação. Formação de Professores de Matemática. Educação a Distância. Educação Matemática no Ensino Superior.

\section{Contributions of Information and Communication Technologies to the education of Mathematics teachers in distance modality}

\begin{abstract}
The present work presents a research that investigated the contributions of Information and Communication Technologies to the Education of Mathematics Teachers in the modality called Distance Education. The theoretical-bibliographic reference includes works of Mathematics Education related to Technologies, Teacher Education and Distance Education. The field research was carried out with undergraduate students in Mathematics in the distance modality Federal University of Ouro Preto (UFOP), located in Minas Gerais from exploratory activities on various contents of Functions of the 1st and 2nd grades, Trigonometric Functions and Polynomial Functions were implemented using the GeoGebra

Frederico da Silva Reis Doutor em Educação. Professor do Programa de Pós-Graduação em Educação Matemática da Universidade Federal de software. The final considerations point out that the main contributions were the development of essential competences and skills of future teachers, in addition to a change of perspective in relation to their future practice pedagogical.
\end{abstract} Ouro Preto (UFOP). Minas Gerais, Brasil.

iD https://orcid.org/0000-0001-6087-6483

$\triangle$ frederico.reis@ufop.edu.br

Fausto Rogério Esteves Mestre em Educação Matemática. Professor da Universidade de Alfenas (UNIFENAS), campus Alfenas. Minas Gerais, Brasil.

https://orcid.org/0000-0003-4753-2453

\fausto-rogerio@hotmail.com

Recebido em 25/09/2020 Aceito em 21/10/2020 Publicado em 24/10/2020

Keywords: Information and Communication Technologies. Education of Mathematics Teachers. Distance Education. Mathematics Education in Higher Education.

\section{Contribuciones de las Tecnologías de la Información y la Comunicación a la formación de profesores de Matemáticas en la modalidad a distancia}

Resumen: El presente trabajo presenta una investigación que investigó los aportes de las Tecnologías de la Información y la Comunicación a la Formación de Profesores de Matemáticas en la modalidad denominada Educación a Distancia. El marco teórico-bibliográfico incluye trabajos de Educación Matemática relacionados con Tecnologías, Formación del Profesorado y Educación a Distancia. La investigación de campo se realizó con estudiantes de pregrado en Matemáticas en la modalidad a distancia de la Universidad Federal de Ouro Preto (UFOP), ubicada en Minas Gerais, a partir de actividades exploratorias sobre diversos contenidos de Funciones de 1er y 2 do grado, Funciones 
Trigonométricas y Funciones Polinomiales, implementadas uso del software GeoGebra. Las consideraciones finales señalan que los principales aportes fueron el desarrollo de competencias y habilidades esenciales de los futuros docentes, además de un cambio de perspectiva en relación a su futura práctica pedagógica.

Palabras clave: Tecnologías de la Información y la Comunicación. Formación de Profesores de Matemáticas. Educación a Distancia. Educación Matemática en la Educación Superior.

\section{Introdução}

As pesquisas em Educação Matemática no Ensino Superior têm mostrado que a utilização das Tecnologias da Informação e Comunicação (TIC) pode contribuir para os processos de ensino e de aprendizagem de Matemática de uma forma realmente inovadora e significativa, não só quando tais pesquisas são relacionadas a conteúdos específicos do Ensino Superior de Matemática, como Cálculo Diferencial e Integral, Geometria Analítica e Álgebra Linear dentre outros (REIS, COMETTI e SANTOS, 2019; RICHIT, 2005; BIANCHINI, LIMA e GOMES, 2019), mas também quando são realizadas tendo como foco a formação de professores de Matemática (BELINE e COSTA, 2010; BITTAR, 2011; LEIVAS, 2009).

Por outro lado, pesquisas também têm apontado que a Educação a Distância (EaD), a partir de seus métodos e formas de ensino e aprendizagem, apresenta características que proporcionam à sociedade uma viabilidade compatível com suas condições de vida, tanto profissional como pessoal, e vem atender à uma demanda específica de alunos, alcançando locais distantes que, dificilmente, seriam atendidos por faculdades ou universidades na oferta de cursos presenciais. Dessa maneira, constitui-se numa forma de democratização do ensino com inovações metodológicas numa educação de futuro, dentro de um processo formativo.

Assim, acreditamos que a utilização das tecnologias na formação de professores de Matemática na modalidade a distância pode contribuir para um repensar sobre o papel do professor na construção de conhecimentos matemáticos e sobre o compromisso que ele deve manifestar com a formação cidadã de seus alunos, numa sociedade cada vez mais impactada pelos avanços tecnológicos.

Portanto, na pesquisa que será delineada a seguir, inicialmente buscando um embasamento teórico-bibliográfico focado em algumas relações entre $\mathrm{EaD}$, TIC e Formação de Professores de Matemática e, posteriormente, detalhando seu contexto e metodologia, objetivaremos investigar a contribuição de atividades utilizando tecnologias para a formação inicial de professores de Matemática na modalidade a distância. 


\section{Estabelecendo algumas perspectivas e críticas sobre a EaD}

No Brasil, a legislação que regulamenta / orienta o processo da EaD tem como marco a Lei de Diretrizes e Bases da Educação Nacional (LDB) no 9394, de 20/12/1996, que prevê no seu Art. 80 que "o Poder Público incentivará o desenvolvimento e a veiculação de programas de ensino a distância, em todos os níveis e modalidades de ensino, e de educação continuada" (BRASIL, 1996). Já os programas de Educação na modalidade a Distância e a utilização de ferramentas tecnológicas no processo educacional foram citados pelo Decreto $n^{0} 5622 / 2005^{1}$, que regulariza 0 Art. 80 da LDB e orienta as instituições de ensino sobre sua organização, oferecimento, avaliação e certificação.

O Decreto traz, no Art. $1^{\circ}$, um novo conceito de $\mathrm{EaD}$, caracterizando-a como uma modalidade educacional na qual "a mediação didático-pedagógica nos processos de ensino e aprendizagem ocorre com a utilização de meios e tecnologias de informação e comunicação, com estudantes e professores desenvolvendo atividades educativas em lugar ou tempo diversos" (BRASIL, 2005).

Entretanto, há de se considerar que, ainda hoje, a EaD é vista por uma boa parte da população brasileira como apenas uma segunda oportunidade para quem abandonou ou não teve acesso ao ensino regular. Borba, Malheiros e Zulatto (2007) fazem um comentário sobre essa visão negativa que o público em geral, e até mesmo alguns educadores, tem sobre a EaD, a respeito da baixa qualidade do seu ensino, que pode prejudicar a formação de profissionais e, em especial, a formação de professores.

Segundo esses autores, o acesso às tecnologias e à internet "são tão importantes quanto garantir lápis, papel e livro para todas as crianças" (BORBA, MALHEIROS e ZULATTO, 2007, p. 17). Apesar disso, é necessário compreender o papel das tecnologias no processo educacional e usá-las adequadamente dentro desse contexto, sendo de suma importância um bom planejamento e um domínio das ferramentas computacionais, possibilitando um atendimento integrado com suporte teórico e prático. Dessa maneira, podem-se obter cursos de qualidade na modalidade a distância, focados na aprendizagem, respeitando o ritmo pessoal, interagindo em grupos e caminhando para uma educação online.

De acordo com Morais (2002), os cursos na modalidade a distância podem fortalecer 0 desenvolvimento de práticas pedagógicas e tecnológicas mas, ao mesmo tempo, também podem provocar uma formação inadequada às novas gerações pois, ao se preocupar com a

\footnotetext{
${ }^{1}$ Revogado pelo Decreto n. 9057, de 25 de maio de 2017.
} 
modernização, aumenta o risco de exclusão, um desafio atual para toda a humanidade. $O$ acesso às tecnologias, segundo essa autora, não é o mais importante, pois no momento que se cuida da aprendizagem, está se cuidando também do indivíduo para vida.

Entretanto, embora aliado às tecnologias, o processo educacional depende de um pensamento sistêmico e transdisciplinar para que o processo de construção do conhecimento seja dinâmico e priorize, numa nova ética consciente, a necessidade de atuar em prol de uma humanidade mais digna e respeitada.

Mudanças profundas ocorreram mundialmente nas últimas décadas, entre elas o avanço das TIC. A relação entre as teorias de informação e dos sistemas e a cibernética induz a necessidade de superar as fronteiras entre as disciplinas escolares. Partindo da transdisciplinaridade, pode-se considerar a incerteza e as contradições como parte da vida e da condição humana e a solidariedade e a ética poderão ser o caminho para a religação dos seres e dos saberes, como defende o sociólogo francês Edgar Morin, o arquiteto da complexidade, que propõe a religação dos saberes com novas concepções, menos simplificadas, sobre 0 conhecimento e a educação. Acreditamos, pois, que, do ponto de vista da educação e, principalmente, da formação de professores de Matemática, é pertinente e se faz necessária uma reflexão sobre o uso das tecnologias e suas implicações.

Por outro lado, temos que considerar, na perspectiva da EaD, que é necessária uma distinção entre transmitir informações e criar condições de construção de conhecimento. A importância do estar junto virtual requer uma interação constante, onde os alunos podem e devem refletir sobre as suas dúvidas com o objetivo de realizar uma espiral de aprendizagem. A abordagem pedagógica é, então, de fundamental importância quanto à sua flexibilidade, propiciando aos alunos a capacidade de criatividade e de geração de conhecimento.

Essa modalidade de educação requer uma interação capaz de associar, numa só dependência, todos os objetivos atribuídos ao ensino e à aprendizagem. Para isso, as questões pedagógicas devem ser tratadas como primordiais para que não se utilizem métodos tradicionais maquiados por recursos tecnológicos digitais. A interpretação e a compreensão da informação fazem parte do produto do processamento que constrói o conhecimento.

O começo desse processo é quando os alunos se envolvem no criar, indagar, questionar; para isso, é necessário que se mostre a eles o caminho da pesquisa, no qual haverá uma série de informações que eles precisarão processar, dando início ao processo de formação do conhecimento. 
Por sua vez, o processo de construção de conhecimento deve ser visto numa perspectiva em que a parte pedagógica seja transformadora. Para Moran (2000), uma análise do futuro seria uma mistura de teleconferência, videoconferência, internet, trabalhos em grupo ou individuais, que podem ser desenvolvidos em momentos distintos, como antes e depois das aulas, tanto online como offline.

Desta maneira, o desenvolvimento de um novo paradigma educacional pode até mesmo manter os currículos como estão, porém, aponta para a necessidade de se repensar a própria prática docente, proporcionando uma interação pertinente à abordagem do estar junto virtual, concebida por Valente (2003), na medida em que

envolve múltiplas interações no sentido de acompanhar e assessorar constantemente 0 aprendiz para poder entender o que ele faz e, assim, propor desafios que 0 auxiliem a atribuir significado ao que está desenvolvendo. Essas interações criam meios para o aprendiz aplicar, transformar e buscar outras informações e, assim, construir novos conhecimentos (p. 31).

Faz-se necessário, neste momento, refletirmos sobre as implicações desse paradigma educacional à luz da utilização das TIC na formação de professores de Matemática na EaD.

\section{Redesenhando relações possíveis entre TIC, EaD e Formação de Professores de Matemática}

As TIC vêm possibilitando a realização e ampliação das atividades em EaD, pois a interação humana está presente nos softwares e nas interfaces, dando a liberdade referente ao tempo e/ou ao espaço. De qualquer maneira, para efetivar essa interação num curso a distância, é necessária uma participação colaborativa, intervindo na comunicação e possibilitando a liberdade de trocas entre as pessoas envolvidas.

Assim como Borba, Malheiros e Zullato (2007), acreditamos que o cotidiano da EaD está relacionado à interação, ao diálogo e à colaboração, fatores que influenciam na qualidade da participação dos envolvidos durante o processo de construção do conhecimento. A troca de ideias, ao se trabalhar o raciocínio e discutir soluções para problemas propostos, permite ao processo uma interação favorável à aprendizagem. O fazer coletivo está relacionado com o diálogo, que é capaz de alcançar um patamar acima de uma simples conversa. Obviamente, nesse fazer coletivo, professores, tutores e alunos têm papéis diferenciados, ainda que fundamentalmente complementares. 
Ferreira e Miorim (2003) chamam a atenção para o fato de que, num processo de aprendizagem, a colaboração é responsável diretamente pelo seu funcionamento, o qual está ligado ao empenho de todos que constroem coletivamente todos os passos para alcançar os objetivos. Porém, a colaboração está vinculada à vontade de cada um em trabalhar junto com 0 outro, fazendo parte de um grupo, de maneira que as relações passem a ser espontâneas, voluntárias e orientadas no sentido de desenvolver as habilidades no tempo e no espaço.

Quando se trabalha junto não necessariamente se pensa uniforme; deve haver contribuição, juntando as individualidades, visando o coletivo, que por sua vez, respeita a individualidade de cada um e a partir de suas diferenças, crescem juntos e constroem seus conhecimentos.

Um ambiente colaborativo requer um respeito mútuo aos saberes conceituais, às experiências de cada participante - professor, tutor, aluno - e um reconhecimento de suas dificuldades, tornando o processo de aprendizagem eficaz dentro do contexto pré-estabelecido. $A$ qualidade da discussão em um Ambiente Virtual de Aprendizagem (AVA) está condicionada ao compromisso, à dedicação e à colaboração quando os interesses individuais são respeitados e valorizados.

Esse trabalho colaborativo deve contribuir para o desenvolvimento profissional dos professores, do ponto de vista de produção de saberes e de reflexão, pois esse trabalho é um processo individual, que depende do desenvolvimento profissional de cada professor e dos momentos compartilhados. Cada interação colaborativa contribui no desenvolvimento profissional do professor, causando uma troca de informações capaz de propor um diálogo com a função principal de orientar a aprendizagem dos alunos.

Nesse sentido, as TIC têm papel importante em cursos de formação de professores, transformando e modificando a maneira de pensar e a prática colaborativa. Em particular, no contexto da Matemática, várias e diferentes mídias podem ser utilizadas com o objetivo de proporcionar uma discussão matemática sobre o modelo educacional que será desenvolvido.

O ambiente virtual possui uma gama de opções — como chat, fórum, portfólio, mural, lista de discussões e outros — que fazem parte do processo educacional num curso a distância. Cada plataforma possui diferentes recursos e cabe ao professor organizador, de acordo com os objetivos pré-estabelecidos, analisar as vantagens e desvantagens das interfaces existentes. 0 modelo escolhido para determinado curso deve estar coerente com as propostas e de acordo com 0 processo utilizado na construção do conhecimento. 
Dentro dessa perspectiva, aponta-se para a formação de um professor que manifeste uma análise crítico-reflexiva sobre sua prática, devendo ser capaz de trabalhar com seus alunos em parceria, promovendo a construção de conhecimento a partir do questionamento, o que leva 0 aluno a construir saberes científicos significativos. A partir das possibilidades proporcionadas pelas TIC, então, a organização hierárquica e os conceitos descontextualizados não fazem sentido, pois a atitude reflexiva supera as habilidades treináveis.

Essa nova postura do professor que se busca assim formar sob novos paradigmas e práticas, coaduna com as ideias propostas por Zeichner (2010, p. 483) que começa por criticar, nos programas tradicionais de formação de professores mantidos por faculdades e universidades, "a falta de conexão entre os cursos de formação de professores nessas unidades e o campo da prática". Para o pesquisador, é necessária

uma mudança na epistemologia da formação do professor, que passa de uma situação em que o conhecimento acadêmico é visto como a fonte legítima do conhecimento sobre o ensino para outra em que diferentes aspectos do saber que existe nas escolas e nas comunidades são incorporados à formação de professores e coexistem num plano mais igualitário com o conhecimento acadêmico (ZEICHNER, 2010, p. 493).

Nessa perspectiva, podemos conceber as TIC como elemento essencial nessa conexão entre o conhecimento acadêmico com o saber experienciado no cotidiano dos professores em formação nas faculdades e universidades. Porquanto, ativa-se nessa discussão, a importância de uma visão de formação de professores como profissionais que a eles forneça "as ferramentas e habilidades de que precisam para serem eficazes no apoio à aprendizagem dos alunos" (ZEICHNER, 2013, p. 36).

Por fim, cabe destacar que, no cerne da discussão sobre a utilização de TIC na formação de professores de Matemática, especialmente na modalidade a distância, encontra-se a busca por um movimento de ensino reflexivo nesse contexto formativo, o qual segundo Zeichner (1993, p. 23), não deve centrar-se apenas na reflexão dos professores na sua própria prática ou nos seus alunos, desprezando-se qualquer consideração das condições sociais do ensino que influenciam o trabalho do professor dentro da sala de aula.

Assim, a utilização de tecnologias permite a reflexão dos futuros professores tanto no momento de sua formação acadêmica, como permite a eles vislumbrar sua utilização numa futura prática pedagógica. Entretanto, nesse movimento é essencial que eles reflitam sobre as condições sociais em que essa prática desenvolver-se-á, bem como seu papel diante do potencial instigador e questionador que as tecnologias catalisam para a sala de aula de Matemática. 


\section{Apresentando a pesquisa em seu contexto}

As discussões sobre as possibilidades didáticas das TIC, à luz da Formação de Professores de Matemática e tendo como contexto a $\mathrm{EaD}$, permitiram-nos realizar uma pesquisa com o objetivo de investigar a contribuição de atividades exploratórias utilizando o software GeoGebra para a formação inicial de professores de Matemática na modalidade a distância.

Com esse foco, uma pesquisa de campo foi realizada com alunos matriculados em uma disciplina intitulada "Prática de Ensino II: Utilização de Tecnologias da Informação e Comunicação na Educação Matemática", disciplina obrigatória do $3^{0}$ período do curso Licenciatura em Matemática na modalidade EaD da Universidade Federal de Ouro Preto (UFOP), instituição que já oferecia os cursos de Licenciatura e Bacharelado em Matemática na modalidade presencial, além do Mestrado Profissional em Educação Matemática.

O curso de Licenciatura em Matemática é oferecido pelo Centro de Educação Aberta e a Distância (CEAD), unidade acadêmica da referida universidade, que oferece cursos de graduação e pós-graduação lato sensu e prima por informatizar diversos polos, em parceria com o governo federal e as prefeituras, para levar a inclusão digital a municípios, com a finalidade de consolidar e aperfeiçoar a EaD.

A pesquisa foi realizada com 116 alunos da primeira turma do curso de Licenciatura em Matemática na modalidade $\mathrm{EaD}$, distribuídos em seis polos localizados em diversas cidades do interior de Minas Gerais. Atualmente, após uma expansão da atuação do CEAD e, com isso, da própria universidade, o referido curso é oferecido em 10 polos localizados em diversas cidades de Minas Gerais (8 polos) e de São Paulo (2 polos).

Cabe ainda destacar que, na estrutura organizacional do curso de Licenciatura em Matemática na modalidade EaD, cada um dos polos possui 2 tutores: um chamado tutor presencial, que atua diretamente no polo e outro, chamado tutor a distância, que atua no próprio CEAD. Assim, os autores do presente trabalho atuaram, respectivamente, como professor responsável e tutor a distância da disciplina na qual a pesquisa foi realizada.

\section{Detalhando a metodologia de pesquisa}

A ementa da disciplina Prática de Ensino II: Utilização de Tecnologias da Informação e Comunicação na Educação Matemática continha os seguintes conteúdos: Contributo das Tecnologias de Informação e Comunicação para o ensino e aprendizagem da Matemática; 
Tecnologias e Educação Matemática; Programas matemáticos: vantagens e desvantagens; Alguns programas matemáticos e suas aplicações para a sala de aula de Matemática; A Internet e seu potencial para a pesquisa e o processo de ensino e aprendizagem.

A carga horária total da disciplina foi de 60 horas/aula, distribuídas nas seguintes atividades: Leitura, discussão e resenhas de textos; Participação em videoconferências; Realização, discussão e avaliação de atividades exploratórias; Elaboração, discussão e avaliação de uma atividade final planejada pelos alunos e implementada em escolas das cidades sedes dos polos. Relatório Final.

Ao longo do semestre letivo foram realizadas quatro videoconferências coordenadas pelo professor responsável e pelo tutor presencial, com a participação dos alunos de quatro polos com vídeo e áudio em tempo real e de dois polos apenas com recepção e interação via internet, pois não possuíam equipamentos para videoconferências, situação bastante comum, especialmente no início do oferecimento de cursos na modalidade a distância em muitas cidades interessadas em oferecer polos.

Dessa forma, após a discussão de textos científicos indicados nas referências da disciplina — artigos, livros e dissertações -, relacionados a Tecnologias da Informação e Comunicação e Educação Matemática, foram planejadas três atividades exploratórias, implementadas ao longo de todo o semestre letivo, voltadas para o ensino de Funções. A escolha do tema Funções se deu pelo fato de já ter sido oferecida, no primeiro período do curso, a disciplina intitulada Introdução à Informática, na qual foram trabalhadas com os alunos atividades de Geometria com a utilização do software GeoGebra. Assim, optamos por explorar os diversos tipos de funções estudadas nos Ensinos Fundamental e Médio, já que a disciplina tinha o caráter de Prática de Ensino.

As atividades exploratórias foram realizadas pelos alunos participantes individualmente ou em grupos, porém, sendo incentivada a sua discussão em grupos ou, se possível, com todos os alunos de um polo. Isto porque alguns alunos de certos polos, especialmente aqueles com número menor de alunos, tinham o hábito de se encontrarem semanalmente em seus polos para realizar as diversas tarefas e/ou trabalhos em grupos.

A implementação das atividades exploratórias ocorreu no laboratório de informática dos polos que o possuíam ou nas casas dos próprios alunos que possuíam computadores, nos quais estavam instalados alguns softwares educacionais, dentro os quais o GeoGebra, utilizado nesta pesquisa. Escolhemos o GeoGebra por se tratar de um software livre, com uma interface de fácil exploração, que traz a possibilidade de se trabalhar conjuntamente as representações algébrica e 
geométrica e possui recursos de movimentos - controle deslizante, caixas de movimentação, dentre outros -, importantes para uma exploração dinâmica dos conteúdos matemáticos.

$\mathrm{Na}$ elaboração das atividades exploratórias, procuramos nos apoiar nas ideias de atividades de investigação e exploração de Reis et al. (2008), trabalho no qual são apresentadas algumas atividades investigativas relacionadas a Funções. Entretanto, devido à forma de acompanhamento das atividades e à sua própria avaliação na modalidade a distância, decidimos por apresentá-las de uma forma exploratoriamente guiada, na perspectiva de Pimentel e Paula (2007) que, ao abordarem a dinâmica dos processos de aprendizagem em uma atividade de investigação, destacam que

as explorações propostas, livres ou guiadas, levavam os alunos a tecerem intuições, inferências e conjecturas que ao serem sistematizadas produziam novas inferências e conjecturas em outro nível de elaboração, que necessitavam de novas sistematizações mais sofisticadas que, por sua vez, levavam a novas inferências, num processo recorrente (PIMENTEL e PAULA, 2007, p. 2).

Acreditamos, como os autores, que uma "multiplicidade de situações, criações e aprendizagens" (PIMENTEL e PAULA, 2007, p. 2) podem emergir no processo de realização de atividades construídas sob essa visão. Assim, optamos por elaborar e propor atividades exploratórias guiadas, no sentido de que o elemento desencadeador da exploração é mais dirigido. Nessa perspectiva, elaboramos e implementamos as seguintes atividades exploratórias: Atividade 1 - Funções Polinomiais do $1^{\circ} \mathrm{e}$ do $2^{\circ}$ grau para $09^{\circ}$ ano do Ensino Fundamental e/ou $1^{\circ}$ ano do Ensino Médio; Atividade 2 - Funções Trigonométricas para o $2^{\circ}$ ano do Ensino Médio; Atividade 3 - Funções Polinomiais para o $3^{\circ}$ ano do Ensino Médio.

Não iremos aqui detalhar as atividades planejadas e implementadas, pois nosso foco não esteve exatamente na parte conteudista das atividades, mas sim na sua forma de realização, uma vez que nossa ideia de exploração guiada perpassou pelo conhecimento matemático mobilizado - definições e principais propriedades das funções abordadas - e desembocou na discussão sobre seu ensino. Assim, após a plotagem dos gráficos e a discussão com seus colegas de grupo e/ou polo a partir da visualização proporcionada pelo software, os próprios alunos foram desafiados a elaborar uma breve sequência para a sala de aula, visando uma real implementação da atividade com alunos, numa aula de Matemática dos Ensinos Fundamental e/ou Médio realizada num laboratório de informática. A discussão das sequências elaboradas pelos alunos foi feita nas videoconferências, momentos nos quais também foram feitas avaliações em conjunto por alunos, professor e tutor, sobre a real viabilidade didática de implementação de cada atividade e das dificuldades do ensino e da aprendizagem dos diversos tópicos abordados. 
Como trabalho final da disciplina, os alunos, reunidos em duplas ou trios, elaboraram uma atividade final utilizando o GeoGebra ou o WinPlot, software do domínio de alguns alunos, versando sobre conteúdos de Álgebra ou Geometria - escolha livre pelos alunos -, que foi implementada com alunos dos Ensinos Fundamental e/ou Médio de escolas públicas ou particulares das cidades sedes dos polos. A implementação destas atividades ocorreu em laboratórios de informática das próprias escolas, que o possuíam, ou dos polos. Em seguida, cada grupo elaborou um relatório final sobre a atividade realizada.

Ainda como parte da coleta de dados, paralelamente à realização das atividades exploratórias, foi feita sua avaliação pelos alunos, por meio de videoconferências e da aplicação de questionários aplicados no início e no final do semestre letivo e também após a realização de cada atividade exploratória, contendo questões abertas, pois as justificativas e descrições apresentadas pelos alunos nos possibilitaram a elaboração de categorias de análise, enquadrando, assim, nossa pesquisa como qualitativa em seus objetivos estabelecidos e nos métodos devidamente escolhidos.

\section{Analisando os questionários em busca da construção de uma "postura docente"}

No Questionário Inicial, buscamos conhecer a visão dos alunos, aqui identificados por nomes fictícios, sobre a importância da utilização das TIC para o professor de Matemática, sendo que eles foram unânimes em afirmar que as tecnologias são de grande valia para a sua prática pedagógica, por auxiliarem os alunos na interação com os colegas, por despertar o interesse dos alunos e por oferecer condições mais acessíveis para a aprendizagem, numa perspectiva muito próxima daquela defendida por Borba e Villarreal (2005).

Um dos aspectos ressaltados foi a contribuição do uso das TIC para uma nova maneira de se fazer Matemática (GRAVINA e SANTAROSA, 1998), como destaca um dos alunos, ao afirmar que "a tecnologia permite que os alunos possam desenvolver um conjunto de habilidades como criar autonomia, aprender a pensar, resolver problemas e analisar as soluções obtidas" (Ana - Questionário Inicial).

Outro ponto destacado é o risco que nós, professores de Matemática, corremos ao nos negarmos a utilizar as tecnologias no ensino, nas palavras de outro aluno:

Se nós, professores, não utilizarmos este interesse deles (dos alunos) por esta nova tecnologia a nosso favor, para despertar a curiosidade e a capacidade de definir e visualizar conceitos que esta máquina nos dá, nossa aula está sujeita a se transformar numa verdadeira decepção para o aluno (Bruno - Questionário Inicial). 
Uma discussão correlata que ocorreu também em algumas videoconferências foi sobre a necessidade de refletirmos sobre o fato de nossa prática pedagógica passar por mudanças estruturais ao longo de nossa carreira docente. Ainda em relação a mudanças, também foi conferida às tecnologias um papel inovador frente à Matemática e seu ensino (SCUCUGLIA, 2006; ACCIOLI, 2005; BORBA, 1999) por outro aluno: "O uso das tecnologias pode promover aos alunos uma mudança no entendimento e no modo de ver e conhecer a Matemática e seu ensino. Caberá ao professor, saber desempenhar um papel de desafiador, mantendo vivo o interesse do aluno" (Carla - Questionário Inicial).

Essas ideias coadunam com as de Valente (2003) ao destacar um novo papel, uma nova postura do professor diante da utilização das TIC no ensino. $O$ aluno afirma que o professor deve "saber desempenhar", o que nos leva a concluir que, ao tratarmos de tecnologias, os próprios saberes docentes têm que ser repensados.

Já em relação às expectativas iniciais em relação à própria disciplina, os principais destaques foram a possibilidade de apreender a utilizar as tecnologias no ensino: "Espero que essa disciplina possa ajudar a identificar quais as melhores maneiras de uso das tecnologias para a abordagem ou para a reflexão sobre um determinado tema ou em um projeto específico, de maneira a aliar as especificidades do suporte pedagógico" (David — Questionário Inicial).

Tal expectativa do aluno parece remeter a mudanças significativas na prática docente (BAIRRAL, 2004), contribuindo para um novo perfil de professor como percebemos nessa outra fala: "Diante dos novos desafios da utilização das TIC na educação, é preciso preparar o professor para entender a abordagem de ensino adotada em sala de aula, fazendo com que o docente deixe a maneira tradicional de ensinar Matemática" (Elisa - Questionário Inicial).

Considerando a necessidade de uma interação entre aluno / professor e professor / aluno visando um ensino de forma criativa e investigativa, num ambiente em que a comunicação seja de qualidade em sala de aula, como uma "aprendizagem pela conversação" (ALRØ e SKOVSMOSE, 2006), outro aluno observou que tal interação poderá gerar mudanças nos papéis dos atores principais desse cenário interativo:

Esta disciplina nos prepara e integra para entender a abordagem de ensino adotada ao perfil do novo aluno. A utilização das TIC no ensino tem que ser feita de forma criativa e investigativa para que o processo de ensino e aprendizagem da Matemática consiga fazer da sala de aula, um ambiente de curiosidade e questionamento, o que poderá e deverá gerar mudanças nos papéis do aluno e principalmente, do professor (Felipe - Questionário Inicial). 
Após a realização de cada atividade exploratória, buscamos investigar por meio de questionários, a visão dos alunos sobre a adequação das atividades aos conteúdos abordados, bem como a possibilidade de sua utilização em sala de aula ou laboratório de informática. De modo geral, os alunos destacaram que as atividades pareceram adequadas aos conteúdos abordados por cada uma delas. Entretanto, foi destacado que, para as escolas adotarem esse novo método de ensino relativo à implementação das atividades, os laboratórios das escolas devem estar preparados para tal implementação, para que os alunos de fato se interessem, pois a visualização é importante e o dinamismo se torna fundamental no processo de construção de conhecimento.

Isso nos remete à perspectiva de Assmann (2004), destacando que formar para as tecnologias é formar o senso crítico, o julgamento, o pensamento hipotético e dedutivo, a observação e a pesquisa. Dentro dessa perspectiva, destacamos a seguinte colocação feita por outro aluno:

\begin{abstract}
Primeiro é preciso que as escolas adotem esse novo método de ensino. A aprendizagem se torna dinâmica e 0 aluno tem a chance de usar o próprio erro para fazer novas descobertas. É esse ambiente que se almeja em sala de aula: alunos participativos, questionadores, curiosos, que buscam suas próprias respostas, ao invés de esperar que elas thes venham prontas, a partir da figura do professor. Com esses recursos, pode-se despertar o interesse do aluno, além de favorecer maior dinamismo às aulas, de proporcionar interatividade e capacidade de inferência, levando-o a construir os seus conceitos acerca do assunto e, assim, participar do processo de aprendizagem (Geraldo - Questionário da Atividade 1).
\end{abstract}

Logo após a realização da Atividade 1, ficou claro que uma "postura docente" estava aflorando naqueles futuros professores. Um exemplo disso ocorreu quando solicitamos sugestões de mudança ou acréscimo na atividade e discutimos sua realização em sala de aula. Em várias falas, eles evidenciaram a necessidade de um professor conhecer bem o software que será utilizado ao apresentá-lo aos seus alunos, com o intuito de familiarizá-los e compartilhar suas ferramentas. Foram também sugeridos alguns acréscimos nas atividades, como por exemplo, trabalhar os pontos de máximo e mínimo das Funções Polinomiais de $2^{\circ}$ grau. Outra valiosa sugestão apresentada se relacionou à construção de tabelas, ao estudo dos sinais das funções, à identificação do domínio, do contradomínio e da imagem, como vemos a seguir:

Poderíamos pedir, em algumas atividades, que eles construíssem uma tabela para conhecerem os pares ordenados da função, com a finalidade de saberem o porquê daqueles pontos. Outra sugestão é definir o domínio, o contradomínio e o conjunto imagem da função, pois é tão importante quanto o estudo dos sinais, um assunto que pode ser muito bem aproveitado com a ajuda dos softwares (Hélio — Questionário da Atividade 1). 
Logo após a realização da Atividade 2, a visualização passou a ser mencionada com maior destaque pelos alunos, muito provavelmente, pelo papel que ela exerce ao propiciar ricas discussões relacionadas às principais características das Funções Trigonométricas. A contribuição da visualização a partir dos gráficos foi o aspecto mais ressaltado devido à possibilidade de percepção de alguns conceitos estudados.

Dessa forma, segundo os alunos, pode-se "visualizar no computador aquilo que foi trabalhado no papel com o lápis". Assim, os alunos foram unânimes em apontar a representação gráfica como foco principal da visualização que permite uma interpretação dos conteúdos trigonométricos desenvolvidos em sala de aula:

\footnotetext{
Este trabalho auxilia a visualização dos conceitos de amplitude, período, deslocamento vertical, deslocamento horizontal, e o que ocorre quando mudamos sinais ou inserimos valores que somados ou multiplicados às funções trigonométricas acarretam mudanças do seu gráfico. Isto ainda contribui para a identificação do gráfico (João Lucas - Questionário da Atividade 2).
}

Outra contribuição destacada consiste na possibilidade de desenvolvimento de um conjunto de habilidades como criar autonomia, aprender a pensar, a criar e resolver problemas e analisar soluções (GRAVINA e SANTAROSA, 1998), conforme observado por outro aluno: "Um dos principais tópicos é visualização dos gráficos das funções. Com a visualização dos gráficos, os alunos podem explorar, investigar, questionar e com isso, é possível contribuir para uma aprendizagem mais significativa" (Luíza - Questionário da Atividade 2).

Finalmente, em relação a sugestões de mudança ou acréscimo na atividade, a maioria dos alunos se manifestou favorável à utilização do software, ressaltando que o professor deve "reforçar" os conteúdos dentro da sala de aula, mostrar como realizar as atividades e, até mesmo, complementar com um pequeno curso de introdução à utilização do software escolhido. Tal manifestação pareceu ainda refletir um pouco da ideia que não se descola da concepção "tradicional" de ensino, de que atividades no laboratório de informática servem como "reforço" dos conteúdos abordados em sala de aula.

Após a realização da Atividade 3, observamos que os futuros professores já se sentiam mais à vontade para vislumbrar possibilidades para a sala de aula de Matemática. Um exemplo que retrata uma situação didática em sala de aula e também retoma a perspectiva trazida por Valente (2003) de que um professor deve pesquisar novos softwares dentro de sua área de atuação e dar oportunidade aos seus alunos para que eles possam fazer o mesmo, pode ser contemplado na seguinte proposta: 
Para a aplicação em sala de aula, seria interessante pedir aos alunos que pesquisem outros softwares em que seja possível a realização deste tipo de atividade; nós, como alunos, conhecemos o GeoGebra, mas os alunos de Ensino Médio e Fundamental não conhecem. Seria interessante que eles tivessem a oportunidade de usar outros softwares, analisando as suas diferenças e opinar qual deles é de sua preferência, pois com isso eles estariam reforçando o aprendizado (Mariana - Questionário da Atividade 3).

Também em relação a sugestões de mudança ou acréscimo na atividade, os alunos apresentaram sugestões didáticas como, por exemplo, diante das dificuldades da análise gráfica das Funções Polinomiais de grau maior ou igual a três, destacadamente a discussão / interpretação sobre a quantidade, a multiplicidade e a natureza das raízes (reais ou complexas), foi apontada pelos alunos a necessidade de uma "revisão teórica" antes da realização da atividade, como vemos a seguir:

Este tipo de atividade precisa de uma revisão teórica antes de ser aplicada, pois somente com um conhecimento prévio sobre o assunto é que se consegue chegar ao objetivo da atividade, que é aprofundar o conhecimento e firmar os conceitos estudados. Além da revisão, é necessária uma instrução sobre o uso do software, pois fica praticamente impossível realizar a atividade, se não tiver uma orientação sobre as ferramentas que o programa dispõe para fazer os gráficos que ele oferece (Paulo Questionário da Atividade 3).

Já no Questionário Final, retomamos a questão da importância da utilização de TIC na prática pedagógica do professor de Matemática e percebemos que o foco das respostas convergiu para a contribuição da utilização das TIC no processo de construção de conhecimento (PENTEADO, 1997), como destaca o seguinte aluno: "Com a presença dos computadores na educação, com os inúmeros jogos educacionais e demais softwares disponíveis para esse processo, se ganham novas possibilidades, são mais recursos a serem integrados como mediadores do ensino-aprendizagem (Ricardo - Questionário Final)".

A contribuição das tecnologias para o processo de reflexão sobre o conhecimento a ser construído, tão destacada em alguns textos trabalhados e, também, alvo de discussões muito interessantes em videoconferências realizadas, apareceu de forma consistente em algumas vozes, como a que segue:

0 ato de ensinar e aprender ganha novo suporte com o uso de diferentes tipos de softwares educacionais, de pesquisas na internet e de outras formas de trabalhos com o computador. Acrescento que o computador com seus inúmeros softwares pode ser uma ferramenta muito importante na mediação do processo da construção do conhecimento, capaz de favorecer a reflexão do aluno, viabilizando a sua interação ativa com determinado conteúdo de uma ou mais disciplinas (Victoria — Questionário Final). 
Finalmente, em relação às contribuições da disciplina, os alunos foram unânimes em afirmar que a disciplina, por meio da realização das atividades e das discussões travadas, correspondeu à expectativa inicial de contribuir para a formação de um novo perfil de professor (MISKULIN et al., 2006).

\section{Contribuições das TIC à Formação de Professores de Matemática na modalidade EaD}

Com base nos dados obtidos em nossa pesquisa, por meio dos diversos procedimentos metodológicos e, destacadamente, a partir das atividades exploratórias implementadas, dos questionários analisados, das discussões dos textos científicos e das videoconferências realizadas, podemos traçar um conjunto de categorias de análise que intentam lançar alguma luz à investigação aqui proposta.

\section{* A contribuição para o desenvolvimento de competências e habilidades}

O uso do computador favorece o desenvolvimento de diversas habilidades e contribui no reconhecimento e orientação das atividades propostas. Nessa perspectiva, as atividades de ensino em ambientes informatizados devem ser elaboradas de forma a permitir que os alunos desenvolvam um conjunto de habilidades fundamentais, como descrevem Gravina e Santarosa (1998).

Nossa pesquisa reforçou o fato de que a utilização de TIC constitui um componente importante no processo que estimula a aprendizagem e a autonomia, criando um espaço favorável para o desenvolvimento de competências e habilidades que serão de fundamental importância na construção do conhecimento matemático.

* A contribuição para uma mudança na postura do professor

A mediação do professor é de vital importância para o processo de aprendizagem e para a construção do conhecimento. Toda aprendizagem se dá no contato do homem com o objeto e, nessa interação, constrói-se assim, um novo conhecimento. Essa construção se acumulará sobre estruturas já existentes, havendo uma maior habilidade e ampliação nas possibilidades de uso das informações adquiridas para adaptar o homem ao meio conforme suas necessidades.

Nossa pesquisa destacou que há a necessidade de uma nova postura do professor comprometido com a construção de conhecimento. O professor deve passar a ser um orientador I mediador, contribuindo para que seus alunos sejam instigadores e questionadores, numa perspectiva muito próxima daquela defendida por Moran (2002). 
* A contribuição para a integração das tecnologias no processo educacional

A sustentabilidade do ensino na modalidade a distância está relacionada com uma série de fatores que compõem o conjunto na sua forma plena de atuar; começando pela formação inicial do professor formado na modalidade a distância, que necessita de uma orientação sobre 0 uso das tecnologias no processo educacional, desde a convivência direta com a máquina, quanto ao seu medo de utilizá-la.

Assim, nossa pesquisa revisita Valente (1999), ao afirmar que, no processo de formação, devem ser criadas as devidas condições para o docente construir seu conhecimento a partir das técnicas computacionais, integrando conteúdos e resolvendo problemas de interesse dos alunos, como destacado por vários dos professores de Matemática em formação.

* A contribuição para a aprendizagem matemática

De acordo com uma nova ênfase educacional, centrada na aprendizagem, o professor é coautor do processo de aprendizagem dos alunos. 0 conhecimento deve ser construído e reconstruído continuamente pois, segundo Almeida (2001), aprender é estabelecer conexões e desenvolver uma interaprendizagem baseada na competência de resolver problemas em grupo.

Nossa pesquisa mostra que é hora, então, de reinventarmos a aprendizagem de Matemática, fazendo com que as tecnologias sejam um elo entre os objetivos que se quer alcançar e o potencial dos alunos. As TIC podem sim desenvolver interaprendizagem, na medida em que são utilizadas de forma colaborativa e reflexiva.

Apesar de delinearmos as diversas contribuições acima, cumpre-nos também destacar os enormes desafios que ainda se apresentam na inserção das TIC, de forma robusta e intencionalmente planejada, na formação de professores de Matemática na modalidade a distância. Outrossim, tais desafios se configuram em uma mola propulsora e incentivadora de futuras investigações no âmbito da Educação Matemática.

\section{Considerações Finais}

Nossa pesquisa, obviamente, não buscou esgotar a questão da utilização de TIC na formação de professores de Matemática na modalidade a distância. Entretanto, pareceu-nos claro que ela foi enriquecida por nossa inserção direta no locus da EaD pois, a partir daí, pudemos vivenciar, como professores-pesquisadores, todos os problemas e dificuldades dessa modalidade de formação. 
Se, por um lado, os alunos de Licenciatura em Matemática na modalidade EaD utilizam as tecnologias diariamente em sua vivência escolar - videoconferências, chats, web-aulas, plataforma etc. - , por outro lado, eles se assemelham, em muitos casos, aos alunos da modalidade presencial e, principalmente, dos (seus futuros) alunos dos Ensinos Fundamental e Médio.

Uma grande parte dos nossos alunos, incluindo os futuros professores de Matemática em formação, seja na modalidade presencial ou a distância, utilizam o computador em casa, mas não conseguem perceber que esse elemento de seu cotidiano possui um enorme potencial na aprendizagem matemática.

Assim, podemos fazer uma correlação de tal fato com a questão da necessidade de uma incorporação da cultura à prática escolar, como defendem Rosa e Orey (2003) no contexto da sala de aula de Matemática:

\begin{abstract}
Um aspecto primordial a ser ressaltado é que os alunos devem ser auxiliados a perceber o potencial matemático que eles possuem através do reconhecimento da importância da cultura para a identidade de cada indivíduo, pois este aspecto afeta 0 modo como cada um pensa, aprende, reflete, conclui e toma decisões. Nas aulas de Matemática, deve-se valorizar entender e compreender a influência que determinada cultura tem sobre a Matemática e como esta influência resulta nas diferentes maneiras sobre as quais a Matemática é pensada, comunicada e transmitida (p. 13).
\end{abstract}

Esperamos, então, que nossa pesquisa possa contribuir para uma mudança de postura, para uma mudança de prática, para uma mudança de pensar, mas principalmente, para uma mudança de cultura, especialmente no contexto da prática pedagógica de professores de Matemática que, no decorrer de sua formação inicial, podem e devem refletir, na perspectiva de Zeichner (1993), sobre as diversas contribuições da utilização das tecnologias tanto ao ensino como para a aprendizagem de conteúdos matemáticos, como algumas aqui apresentadas e discutidas.

\title{
Agradecimentos
}

Aos alunos e professores do Centro de Educação Aberta e a Distância (CEAD), pela participação voluntária em nossa pesquisa e à Coordenação do Mestrado Profissional em Educação Matemática (PPGEDMAT) da Universidade Federal de Ouro Preto (UFOP), pelo apoio à realização da pesquisa. 


\section{Referências}

ACCIOLI, Rosangela Mengai. Robótica e as transformações geométricas: um estudo exploratório com alunos do Ensino Fundamental. 2005. 224f. Dissertação (Mestrado em Educação Matemática) - Faculdade de Ciências Exatas e Tecnologias. Pontifícia Universidade Católica de São Paulo. São Paulo.

ALMEIDA, Maria Elizabeth Biaconcini. Formando professores para atuar em ambientes virtuais de aprendizagem. In: ALMEIDA, Fernando José de. (Org.). Projeto Nave - Educação a distância: formação de professores em ambientes virtuais e colaborativos de aprendizagem. São Paulo: Projeto Nave, 2001, p. 79-82.

ALRØ, Helle; SKOVSMOSE, Ole. Diálogo e aprendizagem em Educação Matemática. Tradução de Orlando de Andrade Figueiredo. Belo Horizonte: Autêntica, 2006.

ASSMANN, Hugo. Reencantar a Educação: rumo à sociedade aprendente. Petrópolis: Vozes, 2004.

BAIRRAL, Marcelo de Almeida. Compartilhando e construindo conhecimento matemático: análise do discurso nos chats. Bolema, Rio Claro, v. 17, n. 22, p. 37-61, set. 2004.

BELINE, Willian; COSTA, Nielce Meneguelo Lobo da. (Org.). Educação Matemática, Tecnologia e Formação de Professores: algumas reflexões. Campo Mourão: FECILCAM, 2010.

BIANCHINI, Barbara Lutaif; LIMA, Gabriel Loureiro; GOMES, Eloiza. Possibilidades de novas pesquisas em Cálculo, Análise e Álgebra Linear a partir de um mapeamento das investigações do GT04. REnCiMa, São Paulo, v. 10, n. 2, p. 112-124, 2019.

BITTAR, Marilena. A abordagem instrumental para o estudo da integração da tecnologia na prática pedagógica do professor de Matemática. Educar em Revista, Curitiba, n. 1, p. 157-171, 2011.

BORBA, Marcelo de Carvalho. Tecnologias Informáticas na Educação Matemática e reorganização do pensamento. In: BICUDO, Maria Aparecida Viggiani. (Org.). Pesquisa em Educação Matemática: concepções e perspectivas. São Paulo: UNESP, 1999, p. 285-295.

BORBA, Marcelo de Carvalho; MALHEIROS, Ana Paula dos Santos; ZULATTO, Rúbia Barcelos Amaral. Educação a distância online. Belo Horizonte: Autêntica, 2007.

BORBA, Marcelo de Carvalho; VILLARREAL, Mónica Ester. Humans-with-Media and the Reorganization of Mathematical Thinking: Information and Communication Technologies, Modeling, Visualization and Experimentation. New York: Springer, 2005.

BRASIL. Decreto n. 5622, de 19 de dezembro de 2005. Regulamenta o art. 80 da Lei no 9.394, de 20 de dezembro de 1996, que estabelece as diretrizes e bases da educação nacional. Brasília: Diário Oficial da União, 20 dez. 2005.

BRASIL. Lei n. 9395, de 20 de dezembro de 1996. Estabelece as diretrizes e bases da educação nacional. Brasília: Diário Oficial da União, 23 dez. 1996.

FERREIRA, Ana Cristina; MIORIM, Maria Ângela 0 grupo de trabalho em Educação Matemática: análise de um processo vivido. In: SEMINÁRIO INTERNACIONAL DE PESQUISA EM EDUCAÇÃO MATEMÁTICA, 2, 2003, Santos. Anais do II SIPEM. São Paulo: SBEM, 2003, p. 120. 
GRAVINA, Maria Alice; SANTAROSA, Lucila Maria Costi. A aprendizagem da Matemática em ambientes informatizados. In: CONGRESSO DA REDE IBEROAMERICANA DE INFORMÁTICA EDUCATIVA, 4, 1998, Brasília. Anais do IV RBIE. Brasília: RBIE, 1998, p. 1-24.

LEIVAS, José Carlos Pinto. Imaginação, Intuição e Visualização: a riqueza de possibilidades da abordagem geométrica no currículo de cursos de Licenciatura de Matemática. 2009. 294f. Tese (Doutorado em Educação) - Setor de Educação. Universidade Federal do Paraná. Curitiba.

MISKULIN, Rosana. Giaretta Sguerra; PEREZ, Geraldo; SILVA, Mariana; MONTREZOR, Camila; SANTOS, Cristiane Rodrigues; TOON, Eduard; LIBONI FILHO, Paulo Antonio; SANTANA, Pedro Henrique. Identificação e análise das dimensões que permeiam a utilização das Tecnologias da Informação e Comunicação nas aulas de Matemática no contexto da formação de professores. Bolema, Rio Claro, v. 19, n. 26, p. 103-123, 2006.

MORAIS, Maria Cândida. (Org.). Educação a Distância: fundamentos e práticas. Campinas: NIED I Unicamp, 2002.

MORAN, José Manuel. Mudar a forma de ensinar e de aprender com as tecnologias. Interações, São Paulo, v. 5, n. 9, p. 57-72, jan./jun. 2000.

MORAN, José Manuel. 0 que é Educação a Distância. 2002. Disponível em: http://www2.eca.usp.br/moran/wp-content/uploads/2013/12/dist.pdf

PENTEADO, Miriam Godoy. O computador na perspectiva do desenvolvimento profissional do professor. 1997. 127f. Tese (Doutorado em Educação) - Faculdade de Educação. Universidade Estadual de Campinas. Campinas.

PIMENTEL, Ricardo Antônio; PAULA, Maria José de. A dinâmica dos processos de aprendizagem em uma atividade de investigação. In: ENCONTRO NACIONAL DE EDUCAÇÃO MATEMÁTICA, 9, 2007, Belo Horizonte. Anais do IX ENEM: Diálogos entre a pesquisa e a prática educativa. Belo Horizonte: SBEM, 2007, p. 1-16.

REIS, Frederico da Silva; ALVES, Davis Oliveira; BRITO, Alexandre Botelho; CAMARGOS, Chrisley Bruno Ribeiro; ESTEVES, Fausto Rogério; MACHADO, Ronaldo Asevedo. Tecnologias Informacionais e Comunicacionais no ensino de Matemática: a produção de atividades investigativas num curso de Mestrado Profissional em Educação Matemática. e-xacta, Belo Horizonte, v. 1, n. 1, p. 1-8, 2008.

REIS, Frederico da Silva; COMETTI, Márcio Antônio; SANTOS, Edson Crisostomo dos. Contribuições do GeoGebra 3D para a aprendizagem de Integrais Múltiplas no Cálculo de Várias Variáveis. REnCiMa, São Paulo, v. 10, n. 2, p. 15-29, 2019.

RICHIT, Adriana. Projetos em Geometria Analítica usando software de Geometria Dinâmica: repensando a formação inicial docente em Matemática. 2005. 215f. Dissertação (Mestrado em Educação Matemática) - Instituto de Geociências e Ciências Exatas. Universidade Estadual Paulista. Rio Claro.

ROSA, Milton; OREY, Daniel Clark. Vinho e Queijo: Etnomatemática e Modelagem! Bolema, Rio Claro, v. 16, n. 20, p. 1-16, 2003.

SCUCUGLIA, Ricardo. A investigação do Teorema Fundamental do Cálculo com calculadoras gráficas. 2006. 145f. Dissertação (Mestrado em Educação Matemática) — Instituto de Geociências 
e Ciências Exatas. Universidade Estadual Paulista. Rio Claro.

VALENTE, José Armando. Criando ambientes de aprendizagem via rede telemática: experiências na formação de professores para o uso da informática na educação. In: VALENTE, José Armando. (Org.). Formação de educadores para o uso da informática na escola. Campinas: NIED I UNICAMP, 2003, p. 1-19.

VALENTE, José Armando. O computador na sociedade do conhecimento. Campinas: NIED I UNICAMP, 1999.

ZEICHNER, Kenneth. A formação reflexiva de professores: ideias e práticas. Tradução de Afonso José Carmona Teixeira, Maria João de Carvalho e Maria Nóvoa. Lisboa: EDUCA, 1993.

ZEICHNER, Kenneth. Políticas de formação de professores nos Estados Unidos: como e por que elas afetam vários países do mundo. Tradução de Cristina Antunes. Belo Horizonte: Autêntica, 2013.

ZEICHNER, Kenneth. Repensando as conexões entre a formação na universidade e as experiências de campo na formação de professores em faculdades e universidades. Tradução de Marcelo de Almeida Pereira. Educação, Santa Maria, v. 35, n. 3, p. 479-504, set./dez. 2010. 